\title{
RESEÑAS
}

\section{Romero Torres, Milagros (Ed.). Barrios Altos: Historia y evolución arquitectónica.}

Lima: Instituto Seminario de Historia Rural Andina; Universidad Nacional Mayor de San Marcos; Pakarina Ediciones, 2019.

Este libro reúne ocho estudios sobre las edificaciones adyacentes al actual Palacio Legislativo en Barrios Altos, a los cuales se debe el título, más un estudio que se concentra en la Plaza Dos de Mayo. La intención central de este conjunto es abrir para los historiadores, el campo del patrimonio arquitectónico como ámbito de investigación. La decisión no resulta caprichosa. Este tipo de patrimonio, que en su concepción moderna alimenta el propio sentido de la nación y las identidades locales y regionales en sus manifestaciones más cercanas y materiales, está marcado ante todo por las variables del tiempo y el cambio, y con ellos del deterioro, la destrucción o la restauración. Pese a lo cual, salvo algunas importantes excepciones, no ha sido un terreno frecuentado por los historiadores profesionales, pero sí por arquitectos y arqueólogos que se han aventurado en él con diversos resultados. Este además nos conduce hacia esa línea cada vez más delgada que ha separado el conocimiento histórico de las necesidades de información de quienes toman decisiones, por ejemplo, en lo que concierne a las políticas de la protección patrimonial.

Bajo estas premisas, un pequeño equipo de jóvenes egresados de la Escuela de Historia de la Universidad de San Marcos dirigidos por Milagros Romero, una historiadora con experiencia en varios proyectos de recuperación del patrimonio arquitectónico en la ciudad de Lima, decidió incursionar en este campo. El libro es el resultado de sus primeros pasos, una especie de sistematización de lo aprendido en el terreno, sin mayores ambiciones que la de poner a prueba las herramientas metodológicas necesarias para adentrase en él. En suma, el libro recoge esos esfuerzos y sus primeros hallazgos nos ofrecen la imagen de un punto concreto de la ciudad que, en términos arquitectónicos, está mutando permanentemente, como efecto de procesos políticos, económicos y sociales más amplios, cuyas consecuencias solo pueden percibirse tomando como referencia extensos arcos temporales.

Cada uno de los estudios va al grano, sin mayores antesalas conceptuales. Gana ante todo una nutrida descripción que va dando cuenta de las edificaciones, sus modificaciones arquitectónicas (a lo largo de siglos en algunos casos), también del cambio en las funciones que adquirió, del tipo de sus ocupantes y sus dueños. Por lo general, acompaña a todo esto una contextualización mayor que muestra las trasformaciones de la propia ciudad de Lima. Además, los estudios son enriquecidos por planos arquitectónicos, fotografías e ilustraciones de las edificaciones que complementan los argumentos de los autores. El tono de la descripción y del contexto histórico, de cada uno de los estudios, han dependido tanto de las fuentes a las que han accedido los jóvenes investigadores en sus indagaciones por los archivos como en su propia experticia. En se sentido, si bien todos cumplen con desarrollar

(C) Los autores. Este artículo es publicado por ISHRA, Revista del Instituto Seminario de Historia Rural Andina de la Facultad de Ciencias Sociales de la Universidad Nacional Mayor de San Marcos. Este es un artículo de acceso abierto, distribuido bajo los términos de la licencia Creative Commons Atribucion - No Comercia Compartir Igual 4.0 Internacional. (http://creativecommons.org/licenses/by-nc-sa/4.0/) que permite el uso no comercial, distribución y reproducción en cualquier medio, siempre que la obra original sea debidamente citada. 
estos campos, el conjunto no es uniforme, entre ellos, se dará cuenta el lector, algunos de los trabajos sobresalen.

Los ocho estudios que se ubican en Barrios Altos son los siguientes: "De inquisidores a salvadores: evolución de los inmuebles de las estaciones de bomberos Roma y Cosmopolitan", de Rolando Arciga Soto; "De convalecientes a artistas: la evolución de la Escuela Nacional de Bellas Artes", a cargo de Francisco Valle Villanueva; "Vocación comercial de Barrios Altos: Casa Manuel de La Torre", de Daniela Arauco; "Casa Pando, de residencia a comercio", estudiado por José Quispe Villanueva; "El colegio de Santo Tomás: historias en un claustro redondo", escrito por Jimmy Tarazona Vivanco; "Quinta de La Caridad: Casa de los Condes de Montemar y Monteblanco, de Milagros Romero; "Espacio y patrimonio. El Colegio Real San Felipe y San Marcos", de Jesús Martínez Laya; "Casa Herrería Montes", escrito a cuatro manos por
José Quispe y Milagros Romero. Al final, como una especie de epílogo fuera de la circunscripción de Barrios Altos, gracias a una licencia de la editora, se nos permite acceder al trabajo de Marlon Gala García: "Plaza Dos de Mayo, puerta de ingreso a la ciudad".

El aporte del libro está, en primer lugar, en la impronta de adentrase en un ámbito de estudio poco visitado todavía, marcar ciertas pautas para avanzar por la novedad, y en el hallazgo de fuentes que puedan alumbrar algunos puntos oscuros de la historia arquitectónica de estas edificaciones. La ausencia más sentida ha sido la formulación de pautas conceptuales y metodológicas que sirvan de brújula al momento de cruzar las fronteras que separan la Historia de la Arquitectura.

\section{Marcos Garfias Dávila}

Instituto de Estudios Peruanos

Publicado online: 12 marzo 2020 